\title{
Study on College Students' Entrepreneurship Education and Entrepreneurship Consciousness
}

\author{
Fangjing Li \\ Xi’an International University, Xi’an, Shaanxi 710077
}

Keywords: Entrepreneurship Education, Entrepreneurship Consciousness, College Students

\begin{abstract}
Since the new century, the domestic wave of entrepreneurship and entrepreneurial research has entered a new stage, entrepreneurial activities have increasingly become the source of innovative economic development, continue to drive high-tech cluster enterprise technology innovation and diffusion. Entrepreneurship and innovation is not only a hot issue of modern economic society, but also an important issue in the study of modern technical economics. The party's 18th report pointed out that "to encourage multi-channel multi-form employment, promote entrepreneurship to promote employment." Modern college students as a special social groups, in higher education and university culture, with professional knowledge and skills and young people themselves Unique spirit of innovation, is the future of the country's major scientific and technological entrepreneurship groups, their entrepreneurial will and entrepreneurial ability of the level of entrepreneurship on the market have a profound impact.
\end{abstract}

\section{Introduction}

The 21st century is the "entrepreneurial era", with the knowledge economy to promote the competition between countries focus on innovation and entrepreneurship level. In the report of the 18th Party Congress, it is pointed out that "to promote the realization of higher quality employment, employment is the foundation of the people's livelihood. To implement the policy of self-employment of workers, market adjustment employment, government promotion of employment and encourage entrepreneurship, More active employment policy. To guide workers to change the concept of employment, to encourage multi-channel multi-form employment, to promote entrepreneurship to promote employment, do a good job of college graduates as the focus of youth employment and rural transfer of labor, urban hardship, retired military employment. At the same time, the Third Plenary Session of the Eighteenth Central Committee also stressed the need to increase entrepreneurship, entrepreneurship to promote the work of the whole society. It can be seen that the employment of college students is a very serious problem now facing our country. Entrepreneurship is one of the most effective ways to promote employment. Encouraging and guiding college students to start their own business are an important way to solve the employment of college students. A country with only a large number of talent reserves is to maintain continuous innovation and continuous innovation ability. In 2010, the Ministry of Education in the "vigorously promote the innovation and entrepreneurship education in colleges and universities and the views of independent entrepreneurship work," that contemporary college students is one of the most innovative, entrepreneurial potential groups to encourage and guide college students to start their own businesses.

\section{Relationship between Entrepreneurship Education and Entrepreneurship}

China's college graduates employment system has undergone a change from the planned economic system under the national "unified system" to the socialist market economic system under the "national policy guidance, graduates choose their own job", initially formed a "market-oriented, government regulation, School recommendation, student and employer two-way choice "employment system. In the case of the oversupply of the job market, entrepreneurship has become 
one of the main ways to solve the problem of college students' employment. Understanding the model of modern college students in China can help to optimize the mode of entrepreneurship education in our country and further improve the entrepreneurial training system of entrepreneurship education. At present, the characteristics and problems of modern college students are mainly reflected in the following aspects:

According to Max's employment statistics for college students in 2013, 2012 undergraduate students focus on the industry's highest concentration of only $6.0 \%, 0.2$ percentage points higher than 2011, other industries are lower than 3.3\%. Although the proportion of self-entrepreneurship of Chinese college students has risen under the impetus of some policies, compared with some developed countries, the proportion of college students choose to start their own businesses is still very small, and there is still a gap with the entrepreneurial level of college students in developed countries. From the perspective of employment guidance over the years, this is due to the traditional concept of employment constraints, colleges and universities to encourage college students to carry out business is also more conservative, the government has not yet provide a more perfect for domestic students entrepreneurial environment, so college students in graduation Later, choose a smaller proportion of independent entrepreneurship.

From the current entrepreneurial environment, many college students on the understanding of entrepreneurship there are still many deficiencies, that entrepreneurship is only by virtue of a certain "theoretical knowledge" can choose to start a business. From the relevant employment survey data show that in 2010 the number of independent entrepreneurship accounted for $6.2 \%$ of the local graduates, but after three years will still be the first choice for business fell to 3.5\%. It can be seen that the lack of knowledge of the market and the accumulation of relevant entrepreneurial experience can not meet the needs of the current independent business only by relying on the study of entrepreneurial theory knowledge during school. In addition, this article in the survey of college students also found that college students understand the entrepreneurial way, that the establishment of individual entrepreneurship companies, and in fact, not only the business, but also including technological innovation, product innovation and many other aspects.

College students are special groups in society, less opportunities for social contact, it is difficult to understand the development of various industries in the market, in the industry selection, to receive less relevant information, often choose the more traditional industries as insurance Entrepreneurial choice. China's entrepreneurship education started late, compared with many developed countries, such as the United Kingdom, the United States, Japan, has not yet formed a complete system of entrepreneurial training system, college students in the weak perception of entrepreneurship. From the perspective of social development, with innovative self-entrepreneurship is more development potential, college students founded only on the basis of innovation is more likely to be successful. Some scholars have pointed out that "modern college students should have the spirit of innovation, with traditional ideas and traditional industry challenges and desire, the government should further improve the environment for college students to start their own businesses, strengthen policy support, such as the provision of small loans, Tax, to provide entrepreneurship training, opening guidance, advisory services follow-up support and other "one-stop" services, so that college students get all-round help and support. "The 21st century, China proposed the construction of innovative society, institutions of higher learning should promote college students in Entrepreneurial activities to play a new consciousness for China to become the foundation of the world economic power.

\section{Recommendations for Improving the Quality of Higher Education Students}

Entrepreneurship education has become an important part of the current era in addition to the education of science and technology culture. Colleges and universities should not only provide cultural knowledge and diploma for college students, but also should cultivate the entrepreneurial ability of college students. The development of entrepreneurship education is an important means for the sustainable development of higher education in our country The Colleges and universities to do business education, from the following aspects: a clear entrepreneurial education goal, improve 
the entrepreneurial curriculum system, the construction of entrepreneurial practice base, the establishment of innovative educational mechanisms.

As the main body of entrepreneurship education, colleges and universities should help college students to establish the correct entrepreneurial attitude and change the concept of college students' entrepreneurship. From the analysis of the attitude of the students at the beginning of the survey can be seen that part of the graduates in the early days of the mentality is not conducive to the future development of entrepreneurial activities, such as the implementation of self-employed pressure and anxiety, worry about business risk, Feel confused, etc., these are not conducive to the future start of business activities. The implementation of entrepreneurial education of college students should first be targeted at cultivating students' entrepreneurial spirit and entrepreneurial consciousness. From the entrepreneur's point of view, we should actively participate in entrepreneurial training courses, entrepreneurial practice, improve their entrepreneurial skills and entrepreneurial quality. From the perspective of institutions of higher learning, entrepreneurship-related training should be extended to all students as much as possible, because some students may have entrepreneurial potential, just did not want to start a business, or lack of entrepreneurial funds to venture. From the perspective of the whole society, many graduates will test civil servants, college entrance examination or examination institutions, as the first choice of occupation, often by the impact of public opinion, blindly apply, institutions of higher learning need to change the choice of college students Concept, to encourage students to correctly treat these social phenomena.

From the current college students to accept the case of entrepreneurial training courses, colleges and universities to open the entrepreneurial training course system lag, many colleges and universities only the entrepreneurial education curriculum classified as elective courses, and improve the efficiency of entrepreneurship is one of the key to improve the entrepreneurial education curriculum System key. For the author's survey, 33.7\% of the students said they had never received an entrepreneurial training course, $47.6 \%$ said that occasionally on the entrepreneurial course, which shows that the current university has not yet entrepreneurship education related training courses into China's institutions of higher learning Education system. Improve the curriculum system of entrepreneurship education, on the one hand to expand the scope of students' knowledge of entrepreneurship, improve students' entrepreneurial knowledge and entrepreneurial skills; the other hand, the establishment of professional entrepreneurship courses can cultivate students' entrepreneurial awareness. Colleges and universities can start from the set of entrepreneurial curriculum system breakthrough, whether it is for the school entrepreneurship course training, or out-of-school business training, to stimulate the entrepreneur's potential is essential.

After joining the WTO, the challenge of higher education from the internationalization is getting bigger and bigger, which requires our country to accelerate the innovation mechanism of entrepreneurship education, so that students become a profound cultural knowledge, good innovation ability and entrepreneurial thinking of the new compound talents, To achieve the strategy of China's talent to lay a solid foundation. In the 18th report, the party pointed out: "to promote the realization of higher quality of employment. Employment is the people's livelihood .To implement the work of independent employment, market adjustment employment, the Government to promote employment and encourage entrepreneurship approach, the implementation of employment priority strategy and more Positive employment policy. "This development report reflects China's scientific concept of development, only to achieve sustainable development of entrepreneurial economy in order to achieve the goal of China's innovative economy. Higher education is the cradle of cultivating innovative talents. With the continuous transformation of market economy, colleges and universities should establish and improve the innovative education system and provide graduates with the entrepreneurial idea to adapt to social development.

College student entrepreneurship is an important force in the development of social economy, college students as a new group into the community, its entrepreneurial no deep understanding of the problems faced by entrepreneurship is not in-depth understanding. After graduating from the entrepreneurial knowledge come from, as an educational institution, should assume this 
responsibility, the main thing is to cultivate the entrepreneurial spirit, entrepreneurial spirit, entrepreneurial spirit and entrepreneurial quality of college students, self-study and practical experience. University as the cradle of cultivating outstanding social talents, should cultivate the entrepreneurial ability of college students, need to make great efforts to do campus business education.

In colleges and universities to better implement entrepreneurship education, we must have both a theoretical knowledge of entrepreneurship, but also entrepreneurial practice ability of teachers, which is the implementation of college education to ensure the effectiveness of entrepreneurship. From the participation of different entrepreneurial activities can be found, all experienced by the entrepreneurial team led by the entrepreneurial activities can be effective in improving the entrepreneurial awareness of college students. Therefore, the effective use of the role of entrepreneurship education in colleges and universities should start from the following: First, reasonable arrangements for the teachers of the teachers, to focus on arrangements or employ practical experience of teachers or excellent entrepreneurs to organize teaching, focusing on training graduates entrepreneurial spirit And entrepreneurship confidence; the second is to organize the theory of deep economic management experts to graduate college students, focusing on college students to understand the recent time and the future of national economic development focus or focus on the field, so that the direction or field of college students have a clear The third is to organize college students to large and medium enterprises and the rapid development of enterprises to practice, focusing on cultivating the practical experience of college students.

\section{Conclusion}

Entrepreneurship is the driving force of economic development, on the one hand can create new wealth for the community, on the one hand can continue to inject new vitality into the market. As a special group of college students, students have unique advantages in entrepreneurship, so college students are indispensable fresh forces in entrepreneurial groups. Therefore, to carry out entrepreneurship education, not only to promote the full employment of college students, but also for the adjustment of economic structure and industrial upgrading to bring a certain impetus, in line with national strategic development direction.

\section{Acknowledgements}

The Project of Xi'an International University

\section{References}

[1] Zhang Xudong, Wang Honglei. Knowledge-oriented college students entrepreneurship education [J]. Heilongjiang Higher Education Research,. 2013 (11)

[2] Jing Yuan. College students entrepreneurial education of the internal and external environment research [J]. Jiangsu Higher Education. 2013 (06)

[3] Deng level. China's college students entrepreneurship education status and countermeasures [J] .National and Social Sciences, 2013 (05)

[4] Wu Xiaoqing. Comparison and thinking of entrepreneurial education in Chinese and American colleges and universities [J]. Education Exploration, 2013 (08)

[5] Shi Yongchuan. Entrepreneurship education to promote the employment of college students [J] .Jiangxi Social Sciences, 2013 (05) 